\title{
Evaluation of cassava germplasm for drought tolerance under field conditions
}

\author{
Eder Jorge de Oliveira - Carolina Vianna Morgante - Saulo de Tarso Aidar • \\ Agnaldo Rodrigues de Melo Chaves - Rafaela Priscila Antonio • \\ Jailson Lopez Cruz • Maurício Antônio Coelho Filho
}

Received: 27 March 2017 / Accepted: 17 July 2017

(C) Springer Science+Business Media B.V. 2017

\begin{abstract}
The development of cassava (Manihot esculenta Crantz) with a high yield under water-deficit conditions is one of the goal of the breeding programs. The objective of this study was to evaluate the performance and to select cassava accessions based on drought tolerance indices and productive potential under water stress. Forty-nine accessions were evaluated for five agronomic traits (plant height- $\mathrm{PH}$, root yield-RoY, shoot yield-ShY, harvest index-HI; and dry matter content of roots-DMC) under full irrigation conditions and drought stress (DS). The accessions were selected based on: (i) high yield under drought conditions (HY-DS) and (ii) high drought tolerance (Dr-To) based on six different indices. Overall, water stress dramatically reduced the traits' means (RoY-72.98\%, ShY-54.95\%, DMC$26.15 \%$, HI-31.05\%, and PH-32.95\%). Low coincidence among the top ten accessions was identified based on HY-DS and Dr-To criteria. Therefore, considering only the most important traits (RoY and ShY), five accessions (BGM0815, BGM0598, 9624-09, BGM0818, and BRS Formosa) presented
\end{abstract}

E. J. de Oliveira $(\bowtie) \cdot$ J. L. Cruz · M. A. C. Filho Embrapa Mandioca e Fruticultura, Rua da Embrapa, Caixa Postal 007, Cruz das Almas, BA 44380-000, Brazil e-mail: eder.oliveira@embrapa.br

C. V. Morgante $\cdot$ S. de Tarso Aidar .

A. R. de Melo Chaves - R. P. Antonio

Embrapa Semiárido, BR 428, Km 152, Zona Rural,

Caixa Postal 23, Petrolina, PE 56302-970, Brazil high HY-DS. In contrast, to Dr-To criterion, eight and nine accessions were selected for high yield of the aerial part (ShY and PH) and roots (RoY and DMC), respectively. The mean productivity, geometric mean productivity, and drought tolerance indices were the most promising to identify genotypes with high agronomic attributes, while drought susceptibility index, susceptibility, and yield stability index were suitable to identify the most drought tolerant accessions. This set of selected accessions can be used in breeding programs aimed at high yield and drought tolerance.

Keywords Breeding - Selection - Water deficit . Manihot esculenta Crantz

\section{Introduction}

Cassava (Manihot esculenta Crantz) is considered a food security crop for several countries in Africa, Asia, and Latin America, mainly due to its ability to produce a reasonable yield in marginal environments with low natural fertility (El-Sharkawy 1993, 2012). It is also considered a cash crop due to the possibility to commercialize the storage root for a variety of purposes including processed food products, starch production and biofuels (Tonukari 2004). In Latin America and Asia, as a cash crop, cassava is often cultivated on extensive plantations with high 
agricultural inputs, but $70 \%$ of global production comes from small farms under varied environments from between $30^{\circ} \mathrm{N}$ and $30^{\circ} \mathrm{S}$, from sea level up to $2000 \mathrm{~m}$ of altitude (Okogbenin et al. 2013), covering an area of more than 18.4 million hectares. This phenotypic plasticity can also be observed for waterdeficit tolerance, as cassava has a relatively high root yield under low rainfall conditions and in low-fertility soils (Bergantin et al. 2004; Aina et al. 2007; Okogbenin et al. 2013).

Even under suboptimal conditions, cassava can maintain its production capacity in areas of less than $500 \mathrm{~mm}$ of rainfall per year and that have high potential for evapotranspiration (El-Sharkawy 2007). Some factors that contribute to cassava's drought tolerance are its high growing efficiency in marginal conditions and the absence of developmental stages that are sensitive to water deficit (except during the first three months of establishment), which allow cassava to survive and be productive under conditions in which other basic food crops would not be able to grow (El-Sharkawy 2007; Okogbenin et al. 2003, 2013).

Currently, a large gap exists between the productive potential of cassava and that obtained by farmers in semiarid regions, as the average root yield in the Northeast of Brazil is $9.5 \mathrm{t} \mathrm{ha}^{-1}$ compared to the $23.6 \mathrm{t} \mathrm{ha}^{-1}$ obtained in some genotypes under experimental conditions of water stress (IBGE 2016; Oliveira et al. 2015). Some hypotheses explaining this enormous difference can be attributed to inadequate strategies of crop management, no use of pesticides or agricultural inputs, and the use of varieties with low yield potential, especially in marginal farming areas. Therefore, it is still possible to increase cassava's yield potential for cultivation in semiarid regions, considering the increase its tolerance to water deficit.

Drought tolerance has been a central theme in cassava research, as global concern about climate change has brought new demands to genetic breeding programs because its consequences increase the risks of global drought (Rizza et al. 2004). Therefore, in the last few years, several studies have been devoted to understanding the mechanisms of cassava tolerance, with a focus on the physiological and transcriptional aspects (Chemonges et al. 2013; Zhao et al. 2015; Fu et al. 2016). However, for several crops, the difficulty in identifying physiological parameters as reliable indicators of drought tolerance suggests that agronomic performance in different years and growing environments is still an important indicator of drought tolerance (Voltas et al. 2005).

One of the first steps in breeding programs for drought tolerance is the characterization of germplasm for water-deficit tolerance. Some studies have reported genetic variability to respond to water deficit in cassava (Bergantin et al. 2004; Aina et al. 2007; Adjebeng-Danquah et al. 2016). However, few research groups have dedicated themselves to learning about the distribution of the genetic diversity of $M$. esculenta and its wild species for selecting parents for crosses.

In Brazil, the semiarid region covers approximately $900 \mathrm{~km}^{2}$ and comprises some Southeast states and most of the northeast, where cassava is cultivated with precipitation levels between 250 and $600 \mathrm{~mm}$ per year, mainly in the summer, and with a negative balance in the majority of the months of the year and a high dryness index (Oliveira et al. 2016). However, the semiarid region of Brazil has the greatest genetic diversity of cassava germplasm to adapt to the water deficit (Aina et al. 2007; El-Sharkawy 2007; Okogbenin et al. 2013) and constitutes an excellent environment for the characterization and selection of genotypes tolerant to this abiotic stress.

As drought is the most significant environmental stress in global agriculture, the development of germplasm with a high yield under drought conditions is one of the main objectives of plant breeding (Cattivelli et al. 2008). Therefore, the main objective of this study was to identify genetic sources of tolerance to water deficit in M. esculenta germplasm through evaluations of the yield and agronomic potential under drought conditions (limited water) and full irrigation for future use as a parent in breeding programs.

\section{Materials and methods}

\section{Field experiment}

The experiments were conducted during the two growing seasons of 2012-2014 at the Bebedouro Experimental Station at Embrapa Semiarid, Petrolina, $\mathrm{PE}$, Brazil $\left(9^{\circ} 22^{\prime} \mathrm{S}, 40^{\circ} 22^{\prime} \mathrm{W}\right.$ at $376 \mathrm{~m}$ altitude $)$. The climate in this region is semiarid with total annual rainfall of $164 \mathrm{~mm}$, with a distribution of $71,49,16$, 
and $27 \mathrm{~mm}$ for the 1st, $2 \mathrm{nd}, 3 \mathrm{rd}$, and 4 th quarter of the experiment, respectively, in 2012/2013, and of $289 \mathrm{~mm}$, with a distribution of $166,58,12$, and $53 \mathrm{~mm}$ for the $1 \mathrm{st}, 2 \mathrm{nd}, 3 \mathrm{rd}$, and 4 th quarter of the experiment, respectively, in 2013/2014.

The soil type of the experimental area was sandy loam in texture. Forty-nine genotypes including local and improved varieties with a history of drought tolerance, either because they had been collected in semiarid regions or had been selected under these conditions, were evaluated in field conditions (Table 1).

The cassava varieties were analyzed under full irrigation (FI) and under drought stress (DS). In both conditions, a completely randomized block design with three (2012/2013) and four (2013/2014) replications was used with 10 plants per plot (two rows with 5 plants) and spacing of $0.90 \mathrm{~m}$ between rows and $0.80 \mathrm{~m}$ between plants. For planting, 16-cm cuttings were used, and all cultural practices recommended for the crop were followed. The plants were fertilized with $81 \mathrm{~kg} \quad \mathrm{P}_{2} \mathrm{O}_{5} \mathrm{ha}^{-1}, \quad 40 \mathrm{~kg} \quad \mathrm{~K}_{2} \mathrm{O} \mathrm{ha}^{-1}$, and $40 \mathrm{~kg} \mathrm{~N} \mathrm{ha}^{-1}$. All dosages of phosphorus and potassium were applied at the time of planting, and the nitrogen fertilizer was applied 45 and 90 days after planting.

All blocks were irrigated up to four months after planting (MAP), and water was supplied every two days by inline dripping $\left(4 \mathrm{~L} \mathrm{~h}^{-1}\right)$ according to the plants' evapotranspiration estimated by using data provided by a meteorological station close to the experimental area. After this period, the irrigation of half of the blocks was suspended until harvest for drought assessment in the 49 genotypes, while irrigation was maintained in the other blocks. The blocks were separated by four rows of cassava to restrict lateral movement of water from the FI block to the DS block. The soil humidity was monitored throughout the experiment by using probes connected to the TDR 100 (Campbell) equipment at $20-30 \mathrm{~cm}$ of soil depth. In the irrigated blocks, the humidity remained constant throughout the experiment period in values close to $20 \%$. In blocks with water deficit, values close to zero were obtained 30 days after irrigation suspension.

\section{Assessment}

Plants were harvested at $12 \mathrm{MAP}$, and the following traits were evaluated: plant height $(\mathrm{PH})$; root yield
(RoY), expressed in $\mathrm{tha}^{-1}$; shoot yield (ShY), expressed in $\mathrm{tha}^{-1}$; harvest index (HI); and dry matter content of the roots (DMC), measured by hydrostatic balance and expressed in percentage, according to Kawano et al. (1987).

\section{Data analysis}

The replications, years, and genotypes were assumed as a random sample of the genetic variability, and, therefore, their interaction terms were defined as random effects, while water stress was considered a fixed effect. A mixed model was used to obtain the best linear unbiased predictors (BLUPs) for each genotype for the combined 2-year data. The mixed model was computed from restricted maximum likelihood estimation (REML) analysis, and we evaluated the significance of variance components for all attributes via the Likelihood Ratio Test, as implemented in the lme4 $\mathrm{R}$ package (Bates et al. 2015).

For all traits, the drought tolerance indices were calculated using the BLUPs by applying the following formulas:

- Geometric mean productivity (GMP): GMP = $(\text { YpxYs })^{0.5}$ (Fernandez 1992)

- Drought tolerance index (DTI):DTI $=(Y p x Y s) /$ $(\tilde{Y} p)^{2}$ (Fernandez 1992)

- Mean productivity (MP): $M P=(Y p+Y s) / 2$ (Rosielle and Hamblin 1981)

- Susceptibility (SUS): $S U S=Y p-Y S$ (Hossain et al. 1990)

- Drought susceptibility index (DSI): $D S I=$ $\left[1-\left(\frac{Y s}{Y_{p}}\right)\right] /[1-(S I)]$, where $S I=1-(\tilde{Y} s / \tilde{Y} p)$ (Fischer and Maurer 1978)

- Yield stability index (YSI): $Y S I=Y s / Y p$ (Bouslama and Schapaugh 1984)

In all formulas, $Y s$ and $Y p$ are the traits of a given genotype under drought and irrigated conditions, respectively, and $\tilde{Y} s$ and $\tilde{Y} p$ are the average of the given trait of all genotypes under drought and irrigated conditions, respectively.

Pearson's correlation coefficients between the BLUPs and traits and the drought tolerance indices were calculated using the $\mathrm{R}$ package corrgram (Friendly 2002). Moreover, a principal component analysis (PCA) was performed to characterize each 
Table 1 Cassava germplasm evaluated for yield and root quality traits under full irrigation and under drought stress

\begin{tabular}{|c|c|c|c|}
\hline Accession & Types & Drought reaction & Selection reason \\
\hline $9624-09$ & Improved & Unknown & High leaf retention \\
\hline BGM0089 & Local variety & Unknown & High leaf retention \\
\hline BGM0096 & Local variety & Unknown & Semiarid collection \\
\hline BGM0116 & Local variety & Tolerant & Semiarid collection \\
\hline BGM0163 & Local variety & Unknown & Semiarid collection \\
\hline BGM0279 & Local variety & Unknown & High leaf retention \\
\hline BGM0331 & Improved & Unknown & High leaf retention \\
\hline BGM0360 & Improved & Unknown & High leaf retention \\
\hline BGM0541 & Local variety & Unknown & High leaf retention \\
\hline BGM0598 & Local variety & Tolerant & High leaf retention \\
\hline BGM0785 & Local variety & Unknown & High leaf retention \\
\hline BGM0815 & Local variety & Unknown & Semiarid collection \\
\hline BGM0818 & Local variety & Unknown & Semiarid collection \\
\hline BGM0856 & Local variety & Unknown & Semiarid collection \\
\hline BGM0876 & Local variety & Susceptible & High leaf retention \\
\hline BGM0908 & Local variety & Susceptible & High leaf retention \\
\hline BGM1171 & Local variety & Unknown & High leaf retention \\
\hline BGM1195 & Local variety & Unknown & High leaf retention \\
\hline BGM1482 & Local variety & Unknown & Semiarid collection \\
\hline BGM2020 & Local variety & Unknown & High leaf retention \\
\hline Branquinha & Local variety & Unknown & Productive variety \\
\hline BRS Amansa Burro & Improved & Tolerant & Tolerant to drought \\
\hline BRS Dourada & Improved & Unknown & Productive variety \\
\hline BRS Formosa & Improved & Tolerant & Tolerant to drought \\
\hline BRS Gema de Ovo & Improved & Tolerant & Tolerant to drought \\
\hline BRS Kiriris & Improved & Tolerant & Tolerant to drought \\
\hline Cacau & Local variety & Susceptible & High leaf retention \\
\hline Cachimbo & Local variety & Susceptible & High leaf retention \\
\hline Do Céu & Local variety & Tolerant & Tolerant to drought \\
\hline Engana Ladrão & Local variety & Tolerant & Tolerant to drought \\
\hline Eucalipto & Local variety & Unknown & High leaf retention \\
\hline GCP-001 & Improved & Tolerant & Tolerant to drought \\
\hline GCP-009 & Improved & Tolerant & Tolerant to drought \\
\hline GCP-014 & Improved & Tolerant & Tolerant to drought \\
\hline GCP-020 & Improved & Tolerant & Tolerant to drought \\
\hline GCP-025 & Improved & Tolerant & Tolerant to drought \\
\hline GCP-043 & Improved & Tolerant & Tolerant to drought \\
\hline GCP-046 & Improved & Tolerant & Tolerant to drought \\
\hline GCP-095 & Improved & Tolerant & Tolerant to drought \\
\hline GCP-128 & Improved & Tolerant & Tolerant to drought \\
\hline GCP-179 & Improved & Tolerant & Tolerant to drought \\
\hline GCP-190 & Improved & Tolerant & Tolerant to drought \\
\hline GCP-194 & Improved & Tolerant & Tolerant to drought \\
\hline GCP-227 & Improved & Tolerant & Tolerant to drought \\
\hline GCP-374 & Improved & Tolerant & Tolerant to drought \\
\hline Mani Branca & Improved & Unknown & High leaf retention \\
\hline
\end{tabular}


Table 1 continued

\begin{tabular}{llll}
\hline Accession & Types & Drought reaction & Selection reason \\
\hline NG310 & Improved & Unknown & High leaf retention \\
Paulo Rosa & Local variety & Susceptible & High leaf retention \\
Sacai & Local variety & Tolerant & Tolerant to drought \\
\hline
\end{tabular}

cassava accession based on its response to different drought tolerance indices within four agronomic groups, using R package factoextra (Kassambara and Mundt 2016). The first two principal components and the corresponding component loading vectors were visualized and summarized in scatterplots, in which principal components were color coded according to their clustering.

\section{Results}

Analysis of variance

The ANOVA results combined over the years revealed a significant effect of the experiments under FI and under DS, indicating that the effects of water deficit affected all agronomic and yield traits evaluated in the cassava accessions (Table 2). The REML estimates of variance components for the random effects are presented in Table 2. Similarly, there were significant differences in all traits when comparing different cassava accessions. On the other hand, the absence of a significant effect for the different years of evaluation of the experiments showed similar behavior of the accessions in the different years under water deficit. All interactions, Year:Stress, Accession:Year, and Accession:Stress, were significant for all traits except for Accession:Stress for PH (Table 2), which indicates the possibility of some inversions in the ranking of the cassava accessions according to the sources of variation evaluated.

The cassava accessions presented wide variation for the various agronomic attributes measured in both treatments (FI and DS) (Table 3). Water stress significantly reduced the mean and variation of traits, especially those related to yield attributes, which suffered the largest reduction, such as RoY (72.98\%) and ShY (54.95\%). The other traits suffered reductions ranging from 26.15 to $32.95 \%$ (DMC and $\mathrm{PH}$, respectively).

Drought tolerance of cassava germplasm

The mean of the best linear unbiased predictors plus the overall mean (uBLUP) for all traits evaluated for the ten accessions with high and low uBLUP in the water-deficit condition are presented in Table 3. Although the averages of the cassava accessions obtained in the irrigated condition were higher than those under water deficit (Table 3), there was little difference in the reduction of the agronomic traits when comparing the averages of the top ten and bottom ten when submitted to water deficit (Table 4). For example, for RoY, DMC, HI, and $\mathrm{PH}$, the reduction under water stress was slightly higher in the bottom ten compared to the top ten. The contrary was observed for ShY, with the highest reduction in the top ten $(55.79 \%)$ compared to the bottom ten $(44.79 \%)$.

Considering the five agronomic traits, we observed low coincidence among the top ten accessions. Only accession BGM0815 matched for RoY, ShY, DMC, $\mathrm{HI}$, and $\mathrm{PH}$ simultaneously. Five other accessions (9624-09, BGM0116, BGM0279, BGM0598, and BRS Formosa) matched for three traits, while seven accessions (BGM0096, BGM0163, BGM0541, BGM0818, BRS Kiriris, Engana Ladrão, and Mani Branca) matched for two traits (Table 4). This shows the difficulty of selecting drought-tolerant cassava accessions, considering all variables analyzed. On the other hand, considering only the most important traits for RoY and propagation material for new crop fields, the accessions BGM0815, BGM0598, 9624-09, and BGM0818 were the most promising in the list of the top ten. However, even though it was not part of the top ten for ShY, the BRS Formosa variety was the most productive under water-deficit conditions (9.94 $\mathrm{tha}^{-1}$ of RoY), which represents $2.32 \mathrm{t} \mathrm{ha}^{-1}$ 
Table 2 Analysis of variance for the traits shoot yield (ShY), root yield (RoY), dry matter content of the roots (DMC), and plant height $(\mathrm{PH})$ of 49 cassava accessions under well-watered and drought-stress conditions over two years at Petrolina-(PE), Brazil

\begin{tabular}{|c|c|c|c|c|}
\hline \multirow[t]{2}{*}{ Source } & \multicolumn{4}{|l|}{ Traits } \\
\hline & \multicolumn{2}{|l|}{ Shoot yield } & \multicolumn{2}{|l|}{ Root yield } \\
\hline Variance components (random effects) & Estimate & $p$ value & Estimate & p-value \\
\hline Year & $21.48 \pm 4.64$ & ns & $1.25 \pm 1.12$ & ns \\
\hline Accession & $12.15 \pm 3.49$ & $*$ & $11.64 \pm 3.41$ & $*$ \\
\hline Year:stress & $20.79 \pm 4.56$ & $* * *$ & $16.93 \pm 4.12$ & $* * *$ \\
\hline Accession:year & $7.44 \pm 2.73$ & $* * *$ & $20.26 \pm 4.50$ & $* * *$ \\
\hline Accession:stress & $10.42 \pm 3.23$ & $* * *$ & $41.7 \pm 6.46$ & $* * *$ \\
\hline Fixed effect parameters & F-statistic & p-value & F-statistic & p-value \\
\hline Drought effect & 238.67 & $*$ & 452.85 & $*$ \\
\hline \multirow[t]{2}{*}{ Source } & \multicolumn{4}{|l|}{ Traits } \\
\hline & \multicolumn{2}{|l|}{ Dry matter content } & \multicolumn{2}{|l|}{ Plant height } \\
\hline Variance components (random effects) & Estimate & p-value & Estimate & p-value \\
\hline Year & $0.001 \pm 0.001$ & ns & - & - \\
\hline Accession & $3.63 \pm 1.91$ & $* *$ & $0.04 \pm 0.02$ & $* *$ \\
\hline Year:stress & $0.78 \pm 0.89$ & $* * *$ & - & - \\
\hline Accession:year & $1.74 \pm 1.32$ & $* * *$ & - & - \\
\hline Accession:stress & $2.08 \pm 1.44$ & $* * *$ & $0.001 \pm 0.001$ & ns \\
\hline Fixed effect parameters & F-statistic & p-value & F-statistic & p-value \\
\hline Drought effect & 683.68 & $* *$ & 46.70 & $* * *$ \\
\hline \multirow[t]{2}{*}{ Source } & & \multicolumn{3}{|l|}{ Traits } \\
\hline & & \multicolumn{3}{|l|}{ Harvest index } \\
\hline Variance components (random effects) & & Estimate & & p-value \\
\hline Year & & $76.01 \pm 8.72$ & & ns \\
\hline Accession & & $66.06 \pm 8.13$ & & $* * *$ \\
\hline Year:stress & & $87.66 \pm 9.36$ & & $* * *$ \\
\hline Accession:year & & $20.01 \pm 4.47$ & & $* *$ \\
\hline Accession:stress & & $32.14 \pm 5.67$ & & $* * *$ \\
\hline Fixed effect parameters & & F-statistic & & p-value \\
\hline Drought effect & & 450.88 & & $*$ \\
\hline
\end{tabular}

ns Non-significant; $0.05 *, 0.01 * *, 0.001 * * *$

more than the second most productive accession under these conditions (9624-09) and $2.92 \mathrm{t} \mathrm{ha}^{-1}$ more than the average of the other top ten accessions. Therefore, the BRS Formosa variety can also be considered an alternative for cultivation in regions with lower rainfall incidence.

Regarding the correlation between drought tolerance indices and uBLUP values obtained for each trait under water-deficit conditions, it was observed for $\mathrm{PH}$, $\mathrm{HI}$, and DMC that the uBLUP had a high positive correlation $(>0.69)$ with mean productivity (MP), geometric mean productivity (GMP), drought tolerance index (DTI), and yield stability index (YSI) (Fig. 1). This positive correlation between the BLUPs from the evaluated traits is explained by the fact that the MP, GMP, and DTI indexes are associated with the highest value of the agronomic trait, regardless the tolerance to water stress. In contrast, there was a negative correlation between the uBLUP values for the PH, HI, and DMC traits with susceptibility (SUS) 
Table 3 Average, minimum, maximum, and decrease of the best linear unbiased predictors plus the overall mean (uBLUP) of some agronomic traits evaluated in 49 cassava accessions averaged over 2 years under drought stress and full irrigation at Petrolina-(PE), Brazil

\begin{tabular}{llrrrl}
\hline Trait & uBLUP & Average & Minimum & Maximum & Reduction (\%) \\
\hline Shoot yield & Full irrigation & 20.27 & 11.29 & 31.64 & 54.95 \\
& Drought stress & 9.13 & 7.48 & 12.37 & \\
Root yield & Full irrigation & 21.89 & 8.88 & 47.72 & 72.98 \\
& Drought stress & 5.91 & 4.09 & 9.94 & \\
Dry matter content & Full irrigation & 31.66 & 26.65 & 34.10 & 26.15 \\
& Drought stress & 23.38 & 16.88 & 25.82 & \\
Plant height & Full irrigation & 2.24 & 1.85 & 2.55 & 32.95 \\
& Drought stress & 1.50 & 1.14 & 1.82 & \\
Harvest index & Full irrigation & 50.95 & 27.36 & 66.83 & 31.05 \\
& Drought stress & 35.13 & 15.96 & 54.11 & \\
\hline
\end{tabular}

and drought susceptibility index (DSI) (Fig. 1), indicating that accessions with higher $\mathrm{PH}, \mathrm{HI}$, and DMC tend to be more susceptible under water-deficit conditions. Indeed, this negative correlation is expected, once higher values of SUS and DSI indicate susceptibility of a given accession. Moreover, the uBLUP of ShY and RoY showed a high positive correlation with the MP, GMP, and DTI; moderate correlation with the SUS, and low correlation with the DSI and YSI (0.09-0.22). These results indicate that, for productive attributes in cassava, mainly RoY and ShY, a higher uBLUP under water stress may indicate the most tolerant accessions (based on the SUS) and, at the same time, high productive performance, although the correlations are considered moderate (variation from 0.50 to 0.52 ).

For drought tolerance indices there was a strong positive correlation between the MP, GMP, and DTI (0.96-1.00) and between the SUS and DSI (0.82-0.95), while a high negative correlation was observed between the DSI and YSI ( -0.95 to -1.00$)$ and the SUS and YSI $(-0.80$ to -0.95$)$ for all agronomic traits (Fig. 1). In addition, the correlations between the SUS and GMP (0.92) were also high for the ShY and RoY traits.

MP calculated as the differences between nonstress and stress conditions, highly depends on yield/trait under irrigated conditions and consequently tends to be higher in genotypes with higher yield/trait potential. In some cases, MP also correlated to Ys combining high yield/trait under stress and non-stress conditions (Cabello et al. 2013). GMP is used when the breeding objective is to test relative performance of the genotypes under favorable and stress conditions, taking into consideration the variability in drought intensity once drought stress can vary in severity in field conditions over years. Moreover, GMP is often used by breeders to evaluate high-yielding genotypes under stressed and optimal conditions even considering that this index is less driven by yield/trait potential than MP (Fernandez 1992). DTI is suitable when the objective is to identify genotypes with high yield in both stressed and non-stressed environments, since in general DTI is highly significantly associated to both Ys and Yp. On the other hand, YSI evaluates the yield/trait under stress relative to its non-stress evaluation, and as a result, the genotypes with a high YSI are expected to have high performance under stress. SUS is the differences of the trait between the stress and non-stress environments, in which higher SUS values indicate susceptibility to drought, and in general TOL is efficient in picking up of stress tolerant genotypes but with less yield/trait output. DSI is used to assesses the trait reduction in unfavorable compared with favorable environments, and in general depends not only on Ys and Yp but also on stress intensity, meaning that lower SSI values indicate more resistance to drought, since the yield/trait reduction in drought environments is smaller than the mean yield reduction of all genotypes. Therefore, MP, GMP, and DTI indicate the yield potential of the genotypes regardless its drought tolerance, being useful for maximizing yield in environments where drought occurs occasionally, while SUS, DSI, and SSI are associated with the drought tolerance regardless the yield of the accessions. 


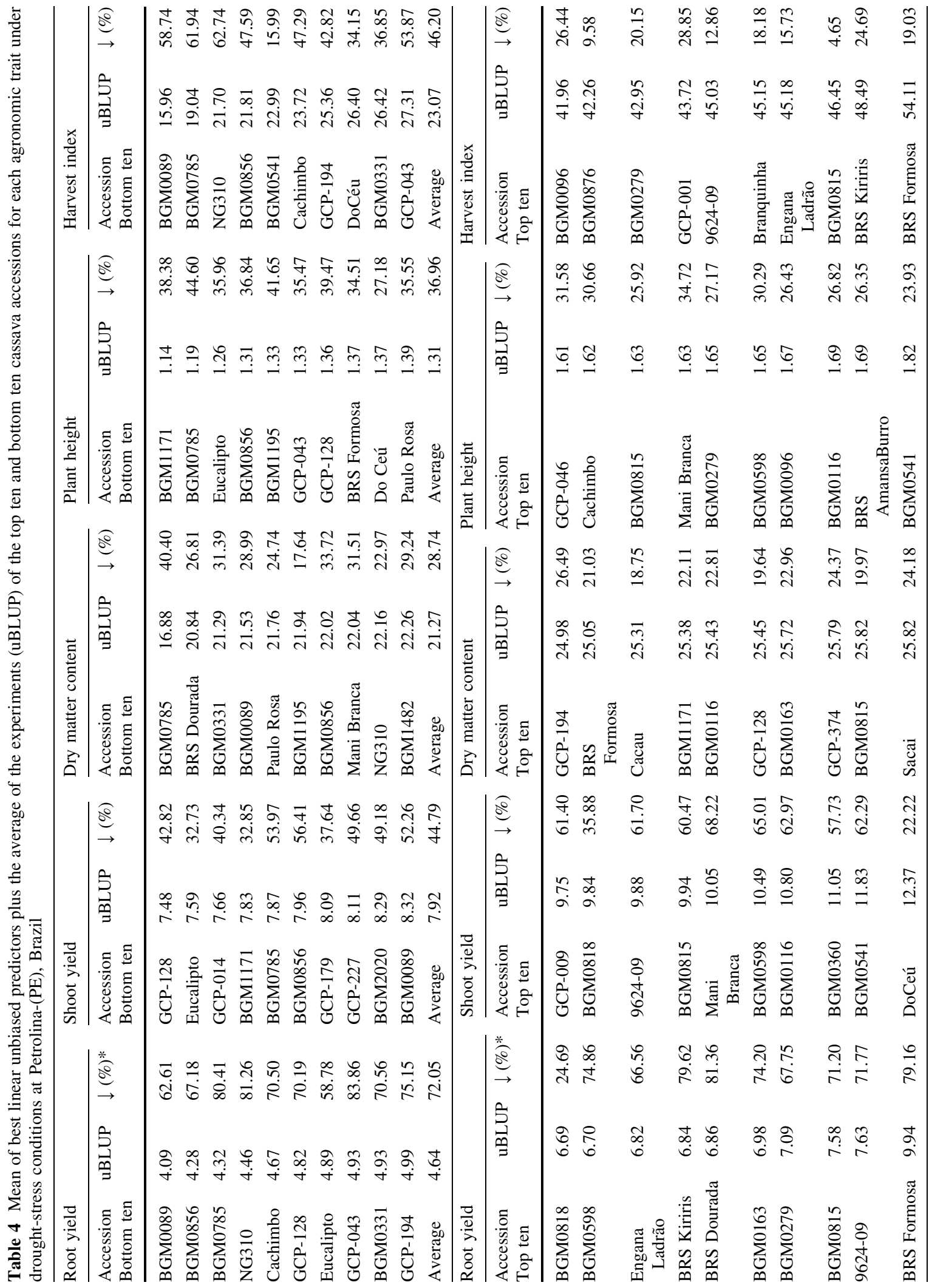


Principal component analysis (PCA) was performed based on the uBLUP under water stress and considering the drought tolerance indices, and then was submitted to biplot analysis to obtain the relationships between those indices and cassava accessions (Figs. 2, $3,4,5$ and 6). In relation to the clustering of accessions based on the agronomic traits and the drought tolerance indices, the Group 3 (formed by the accessions BGM0818, BGM1171, Do Ceú, Eucalipto, GCP-014, GCP- GCP-179, and GCP-190) was the most tolerant to water deficit considering the ShY since it presented a lower DSI and SUS and higher YSI, while Group 2 (BGM0116, BGM0360, BGM0541, BGM0598, and Mani Branca) was considered the most susceptible because it presented contrary trends to those of Group 3. On the other hand, Group 2 presented a higher DTI, GMP, MP, and uBLUP, indicating that its accessions had high yield potential when submitted to FI. The ShY of accessions from Groups 3 and 2 ranged from 8.69 to $10.84 \mathrm{t} \mathrm{ha}^{-1}$, respectively (Fig. 2), which indicates the great difference in ShY when comparing these two groups.

For RoY, Group 1 (formed by the accessions BGM0089, BGM0541, BGM0818, BGM1171, Do Céu, Eucalipto, and Paulo Rosa) was the most tolerant to water deficit (low DSI and SUS and high YSI), while Group 2 (9624-09, BGM0096, BGM0163, BGM0360, BGM0598, BGM0815, BGM0908, BGM1482, BRS Dourada, BRS Kiriris, GCP-001, GCP-009, GCP-020, GCP-043, GCP-190, and Mani Branca) and Group 4 (BRS Formosa) were the most susceptible (high DSI and SUS and low YSI). Similar to ShY, the RoY of BRS Formosa, belonging to Group 4, also had a high DTI, GMP, MP, and uBLUP (Fig. 3). Despite being considered susceptible, BRS Formosa was the most productive accession in the water-deficit conditions, reaching an average of $9.94 \mathrm{tha}^{-1}$ compared to the average of $5.83 \mathrm{tha}^{-1}$ of the other groups. However, accessions from Group 2 presented intermediate values of the DTI, GMP, MP, and UBLUP.

For the DMC, the accessions from Group 4 (BGM0279, BGM1195, BRS Dourada, Cachimbo, Engana Ladrão, Eucalipto, GCP-020, NG310, and Paulo Rosa) and Group 3 (BGM0116, BGM0163, BGM0598, BGM0815, BGM0876, BGM1171, BGM2020, GCP-009, GCP-025, GCP-043, GCP- 
Fig. 1 Pearson correlation between the best linear unbiased predictors plus the average of the experiments and drought tolerance indices for plant height (PH), root yield (RoY), shoot yield (ShY), harvest index (HI), and dry matter content of the roots (DMC) under drought-stress conditions. (MP) mean productivity, (GMP) geometric mean productivity, (SUS) susceptibility, (DTI) drought tolerance index, (DSI) drought susceptibility index, and (YSI) yield stability index
Shoot yield

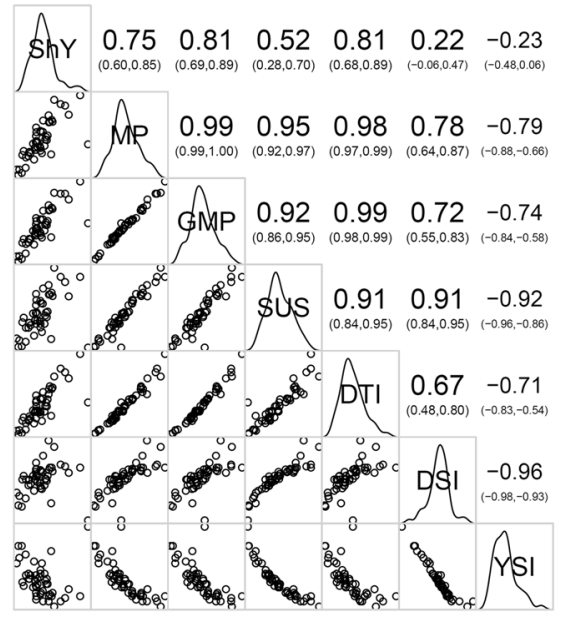

Dry matter content

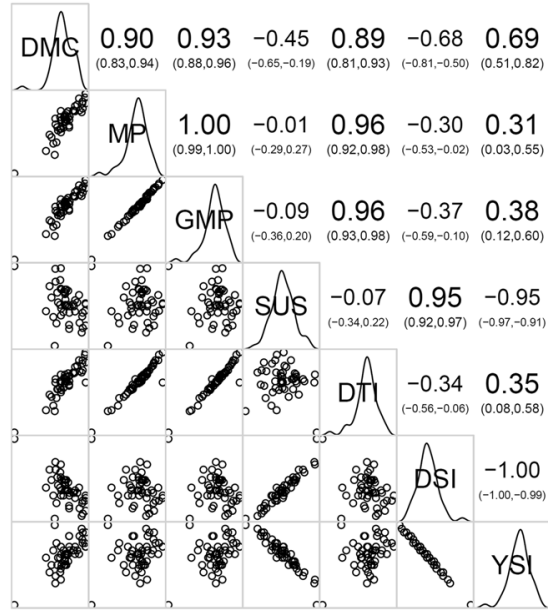

Root yield

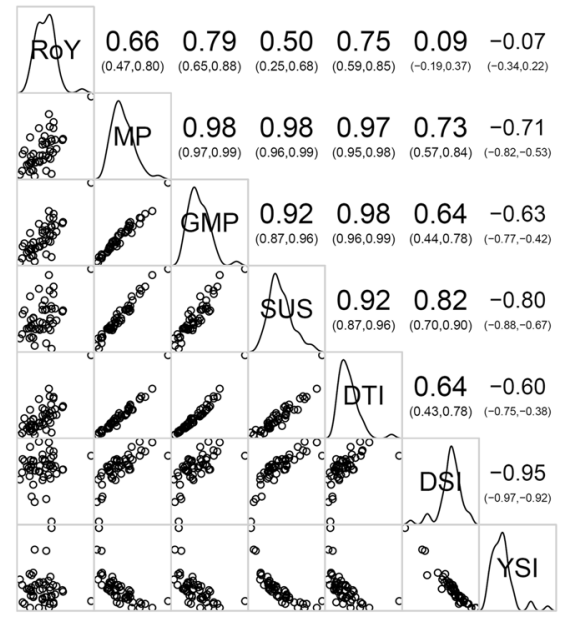

Plant height

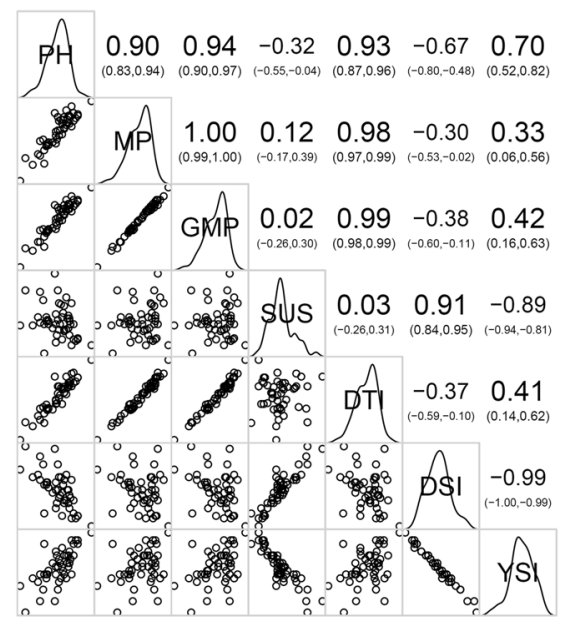

Harvest index

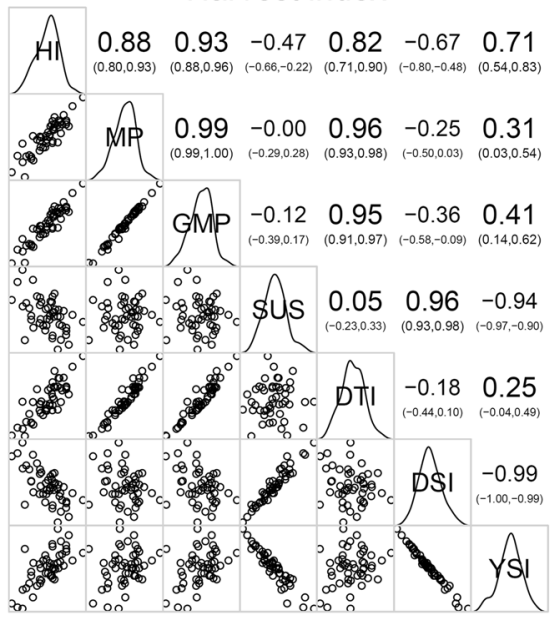


128, GCP-194, GCP-374, Cacau, BRS Formosa, BRS Gema de Ovo, and Sacai) were considered to be the most tolerant to water deficit (low DSI and SUS and high YSI), while Group 1 (BGM0785) (high DSI and SUS and low YSI) was the most susceptible (Fig. 4). However, unlike the ShY and RoY traits, the DMC of the BGM0785 accession presented the lowest DTI, GMP, MP, and uBLUP, being a very susceptible genetic material to drought, with low agronomic performance. In contrast, the accessions from Group 2 (9624-09, BGM0096, BGM0089, BGM0331, BGM0360, BGM0541, BGM0818, BGM0856, BGM0908, BGM1482, Branquinha, BRS Amansa Burro, BRS Kiriris, Do Ceú, GCP-001, GCP-014, GCP-046, GCP-095, GCP-179, GCP-190, GCP-227, and Mani Branca) showed intermediate behavior in relation to DMC and water-deficit tolerance.

For PH, Group 4 (BGM0096, BGM0116, BGM0279, BGM0331, BGM0541, BGM0598, BGM0815, BGM1482, BRS Amansa Burro, Cachimbo, Sacai, Branquinha, Cacau, GCP-020, GCP-046, and GCP-227) was the most tolerant to water deficit (lower DSI and SUS and high YSI), whereas the accessions from Group 3 (BGM0785, BGM0856, BGM1171, BGM1195, Eucalipto, GCP043, and GCP-128) were the most susceptible (high DSI and SUS and low YSI) (Fig. 5). Some accessions from the susceptible (Group 3) and tolerant groups (Group 4) presented a lower DTI, GMP, MP, and uBLUP, characterizing the presence of accessions with high $\mathrm{PH}$ in both groups. The averages of $\mathrm{PH}$ from Groups 3 and 4 were 1.33 and $1.66 \mathrm{~m}$, respectively, compared to 1.45 and $1.55 \mathrm{~m}$ for Groups 1 and 2, respectively (Fig. 5).

Regarding the HI, the Group 4 (9624-09, BGM0279, BGM0815, BGM0818, BGM0876, BGM1171, Branquinha, BRS Formosa, BRS Kiriris, Cacau, Engana Ladrão, and GCP-374) and the Group 2 (BGM0089, BGM0785, BGM0856, Cachimbo, GCP-043, GCP-194, and NG310), were the most tolerant and susceptible to water deficit, respectively (Fig. 6). Besides the tolerance to water deficit, considering the drought tolerance indices, the accessions from Group 4 presented high HI (43.94\%) in comparison with Groups 1, 2 and 3, which was 36.78 , 22.13 , and $29.64 \%$, respectively.

Similar to the observations of uBLUPs obtained under water-deficit conditions, there was also a low coincidence between the cassava accessions considered tolerant based on the drought tolerance indices (Figs. 2, 3, 4, 5 and 6). No cassava accession was considered drought tolerant for all traits based on these indices. However, accessions BGM0116 and Cachimbo were considered tolerant for RoY, DMC, and PH, while accessions BGM1171, GCP-128, and Eucalipto were considered tolerant for the RoY, ShY, and DMC traits.

Due to the difficulty of identifying the most drought-tolerant cassava accessions based on all the agronomic traits simultaneously, the accessions were classified according to aerial part production (ShY and $\mathrm{PH}$ ) and root production (RoY and DMC) for practical purposes of implementing crossing blocks to generate segregated populations. Using these criteria, the accessions BGM0279, BGM0096, BRS Amansa Burro, Cachimbo, BGM0331, BGM0818, Do Ceú, and GCP-190 were the most tolerant for agronomic attributes related to aerial part production, while accessions BGM2020, BGM0876, BRS Gema de Ovo, Paulo Rosa, Cachimbo, BGM0116, BGM1171, GCP-128, and Eucalipto were the most tolerant for traits related to root production. Among these accessions, only BGM0116, BGM0279, and BGM0818 were also classified with a higher uBLUP, indicating the discrepancy of identifying the more tolerant accessions with higher agronomic value in waterdeficit conditions.

\section{Discussion}

Effects of water stress on productive traits

The monitoring of the water stress level imposed in the trials during the evaluation years enabled the creation of precisely managed stress intensity that was distinct from the irrigated environment, as verified in the analysis of variance (Table 2). The reduction in agronomic attributes varied according to the evaluated trait, being $26.15 \%$ for DMC, $32.95 \%$ for $\mathrm{PH}, 54.95 \%$ for ShY, 31.05\% for HI, and $72.98 \%$ for RoY when the water deficit was imposed. This reduction in RoY was higher than the $38.53 \%$ observed by Adjebeng-Danquah et al. (2016) when evaluating 20 cassava accessions in Ghana at different harvest times but was similar to the RoY loss of $87 \%$ observed by Aina et al. (2007) when evaluating nine cassava genotypes in Nigeria. Aina et al. (2007) also reported reductions 


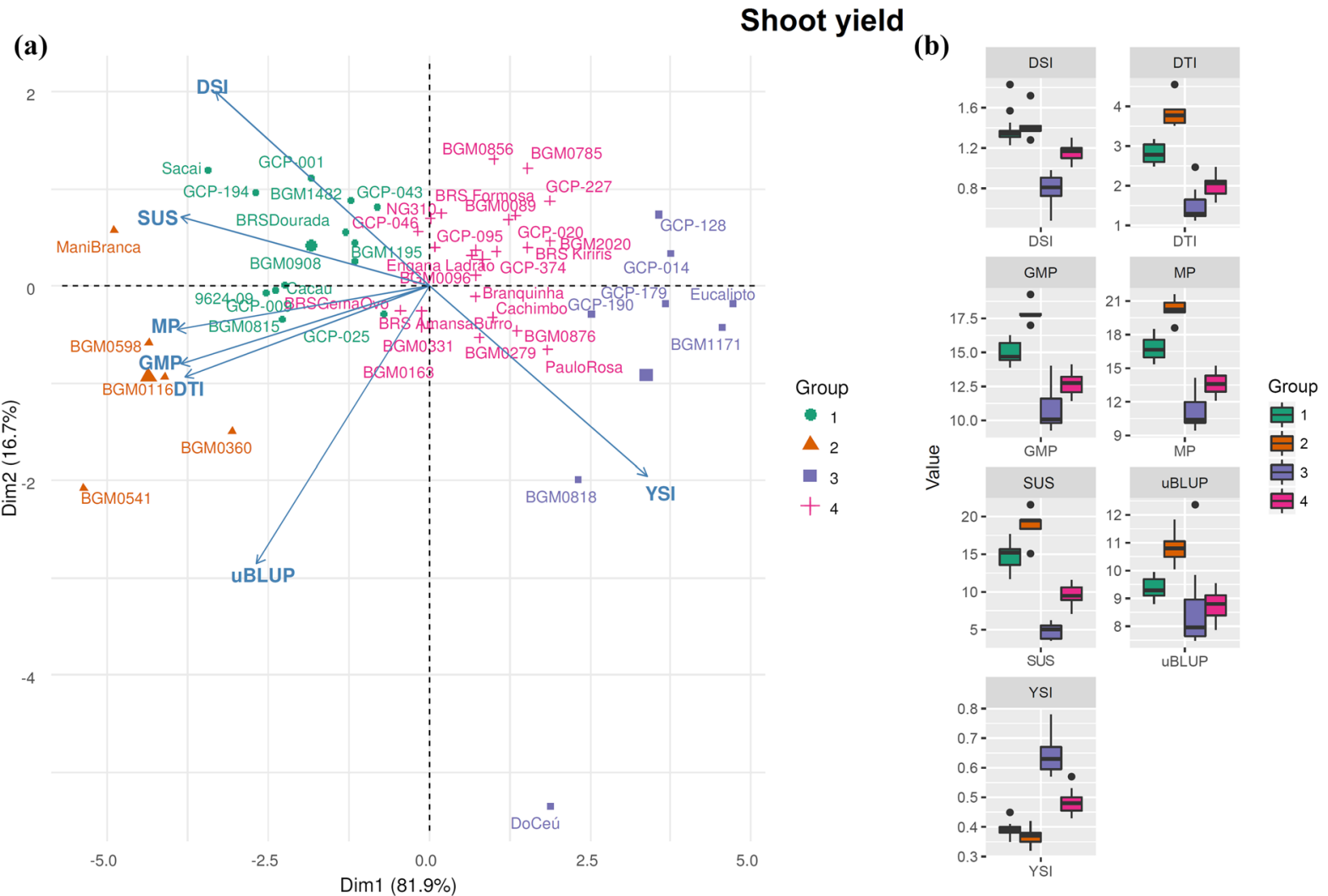

Fig. 2 a Principal component analysis of the 49 cassava accessions based on the best linear unbiased predictors plus the average of the experiments (uBLUP) for shoot yield and several drought tolerance indices. b Boxplot of shoot yield

in $\mathrm{PH}(47 \%)$ quite similar to the $32.95 \%$ observed in the present study. On the other hand, Okogbenin et al. (2013) observed a higher reduction in ShY (37\%) compared to RoY (22\%), particularly in varieties with more vigorous vegetative growth. Many of these differences in losses caused by water stress are related to the genetic material used as well as the stress conditions imposed on the experiments.

As in other studies on tolerance to water deficit in cassava (Aina et al. 2007; Okogbenin et al. 2013), the most pronounced effect of drought stress occurred in yield traits (ShY-54.95\% and RoY$72.98 \%$ ). This can be explained by the fact that tolerance mechanisms in cassava promote a temporarily interruption in the division of assimilates for formation and roots filling, and the plants allocate more assimilates for deep growth of fibrous roots to access water (Duque and Setter 2013) and maintenance of leaf and stem primordia that can
(uBLUP) and drought tolerance indices per group. MP mean productivity, GMP geometric mean productivity, SUS susceptibility, DTI drought tolerance index, DSI drought susceptibility index, and YSI yield stability index

regrow rapidly after resumption of rainfall (Alves and Setter 2004). Although cassava can survive in these adverse conditions, there always will be important economic losses in crop yield. In addition, during the first three months, cassava accumulates more dry matter in the leaves than in the stems and roots. After the third month, there is more accumulation of dry matter in the roots compared to the rest of the plant (Okogbenin et al. 2013). Therefore, the water stress was quite pronounced at the time of high biomass accumulation in the roots. Indeed, it was confirmed by the reduction of the HI $(31.05 \%)$ in drought stress experiments in comparison with full irrigation. Therefore, it is possible that the plant stock, stored as starch in the roots, has been used to guarantee the plant survival during the water stress period. In greenhouse experiments, Bergantin et al. (2004) also reported that plants under water stress had a significant reduction in $\mathrm{PH}$, leaf number, and 


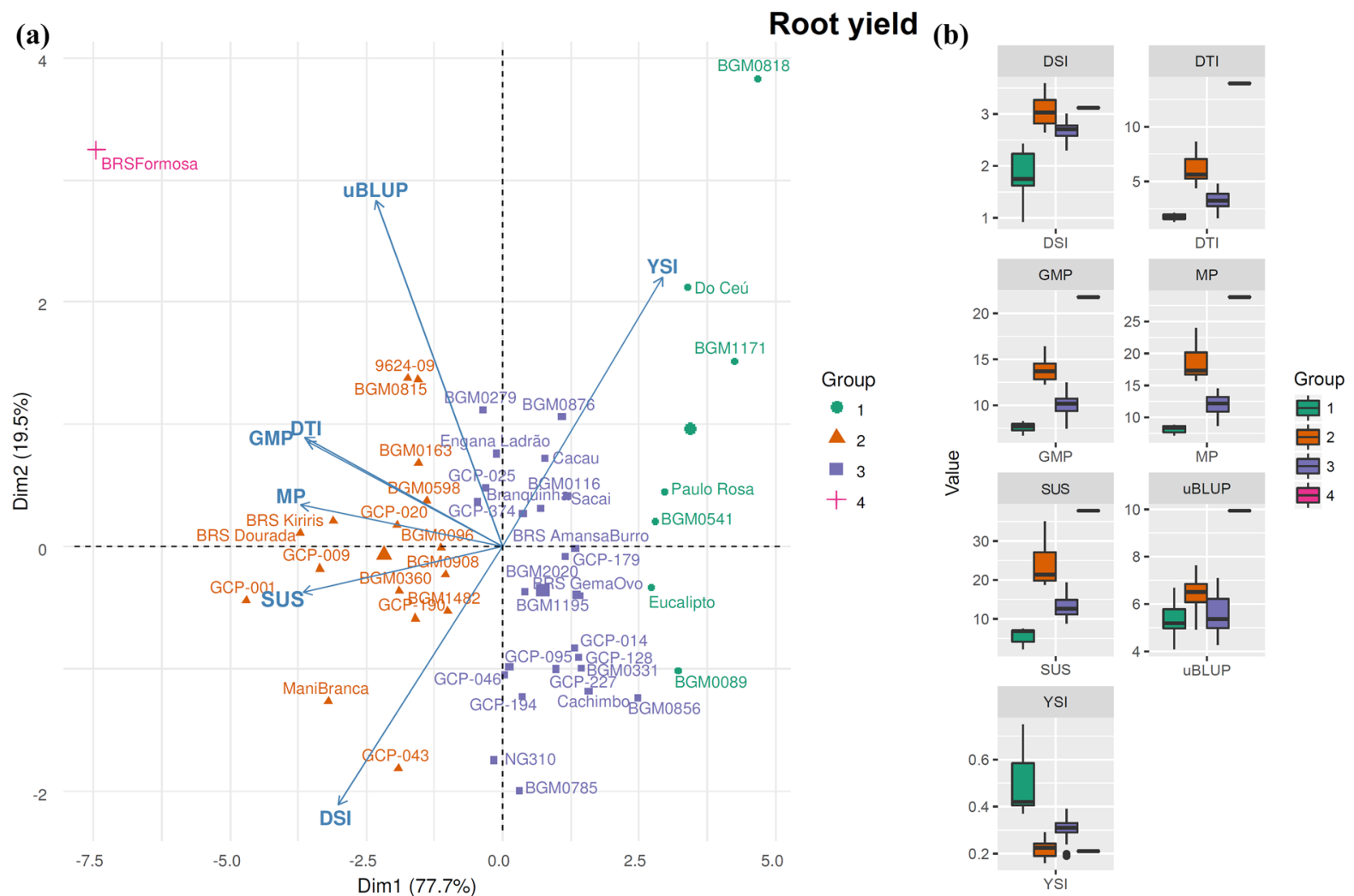

Fig. 3 a Principal component analysis of the 49 cassava accessions based on the best linear unbiased predictors plus the average of the experiments (uBLUP) for root yield and several drought tolerance indices. b Boxplot of root yield

shoot dry weight, and they still presented high stomatal resistance and a low rate of transcription.

The existence of significant effects of interaction between accession and drought stress suggests the presence of inconsistent performance over the two years of evaluation. Similar observations were also reported in greenhouse experiments (Bergantin et al. 2004; Chemonges et al. 2013), indicating contrasting reactions of the cassava genotypes in different soil moisture conditions. Therefore, since cassava accessions were not consistent in their agronomic performance over the years, superior genotypes with high drought tolerance and yield should be selected only in environments under water stress since their behavior under irrigated conditions may not reflect their drought tolerance.

The mean RoY of $7.31 \mathrm{t} \mathrm{ha}^{-1}$ of the top ten accessions under water stress was much lower than the $16.34 \mathrm{tha}^{-1}$ observed in Ghana by Adjebeng-
(uBLUP) and drought tolerance indices per group. $M P$ mean productivity, GMP geometric mean productivity, SUS susceptibility, DTI drought tolerance index, DSI drought susceptibility index, and YSI yield stability index

Danquah et al. (2016) in harvests at 12 months after planting. Conversely, Aina et al. (2007) reported an average RoY below that found in the present study in two environments with severe water stress in Nigeria (2.82 $\mathrm{t} \mathrm{ha}^{-1}$ in Mallamadori and $5.43 \mathrm{t} \mathrm{ha}^{-1}$ in Zaria). Some hypotheses to explain this difference in RoY refer to the use of different genetic materials as well as differences in stress conditions imposed on the experiments because in the present work the average amount of rainfall within the growth cycle was $226 \mathrm{~mm}$, compared to $1180 \mathrm{~mm}$ in Ghana (Adjebeng-Danquah et al. 2016), $850 \mathrm{~mm}$ in Zaria, and $650 \mathrm{~mm}$ in Mallamadori, the latter two both in Nigeria (Aina et al. 2007). Some authors have reported that evaluating bean genotypes under conditions of extreme water stress reduces seed yield at very low levels, which could null the genotypic differences between the materials being evaluated (Ambachew et al. 2015). In contrast, in the present study, even 


\section{Dry matter content}

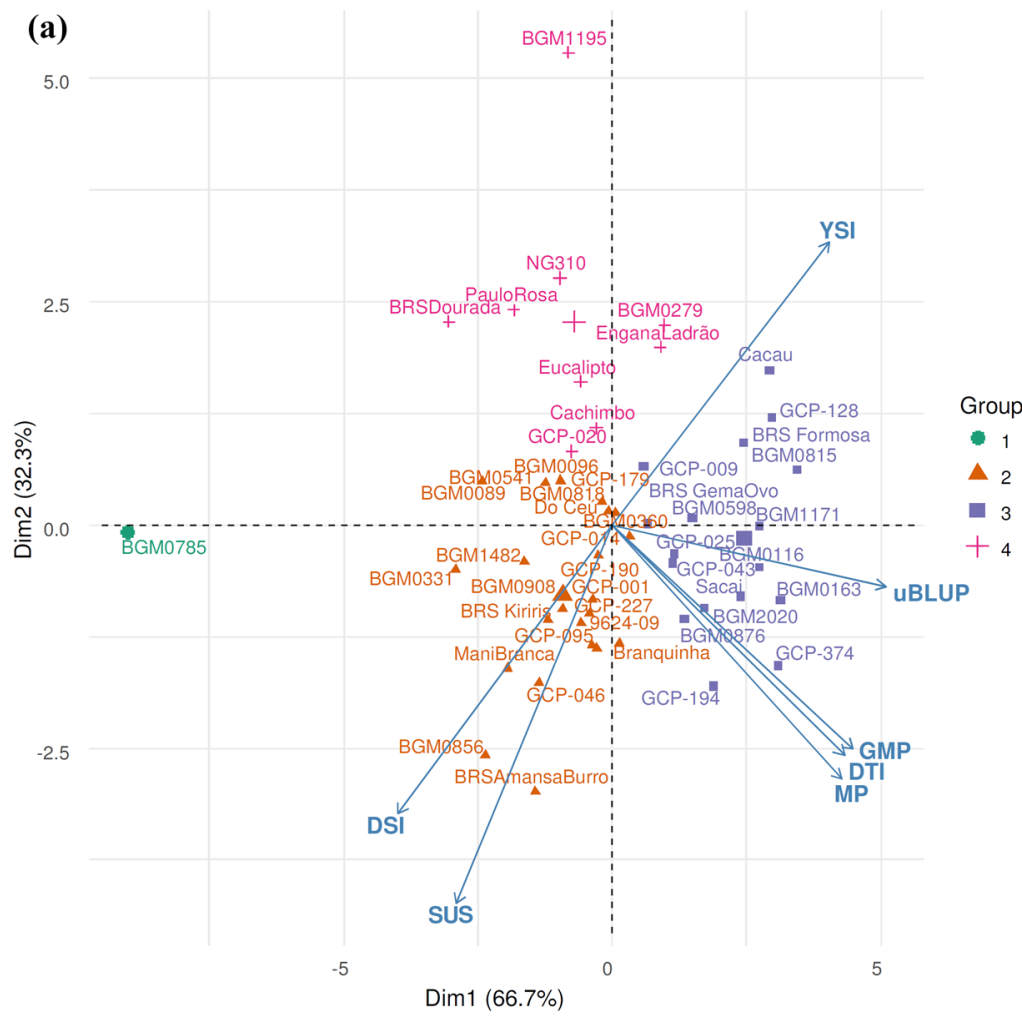

(b)

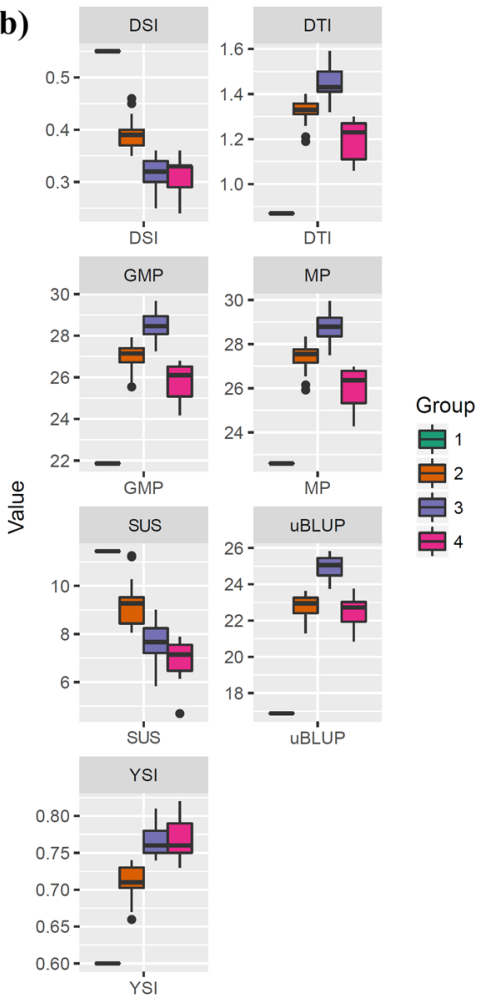

Fig. 4 a Principal component analysis of the 49 cassava accessions based on the best linear unbiased predictors plus the average of the experiments (uBLUP) for dry matter content and several drought tolerance indices. b Boxplot of dry matter

when using extremely adverse climatic conditions for the cassava crop, genetic differences for the four agronomic traits were observed.

The reduction in the agronomic traits' values when submitted to the water deficit was slightly higher in the worst accessions (bottom ten) compared to the best ones (top ten) for most of the traits, except for ShY (Table 4). This indicates that water stress in cassava affected the agronomic performance of accessions in a relatively similar way. Other reports on cassava showed small differences in RoY reduction at 12 months after planting, but these differences were higher in the top ten $(40.24 \%)$ compared to bottom ten (36.34\%) (Adjebeng-Danquah et al. 2016). On the other hand, in other crops, such as rapeseed, there were also larger reductions in the seed yield of the bottom ten compared to the top ten seeds, whose reduction difference ranged from $11.42 \%$ in 2008/2009 to $7.34 \%$ in 2009/2010 (Shirani Rad and Abbasian 2011). content (uBLUP) and drought tolerance indices per group. $M P$ mean productivity, GMP geometric mean productivity, $S U S$ susceptibility, DTI drought tolerance index, DSI drought susceptibility index, and YSI yield stability index

Selection based on drought tolerance indices

The correlation coefficients between the traits in the irrigated and water-deficit conditions and the drought tolerance indices can be used to determine the most suitable of them for selecting the best varieties. Generally, indices that have a high correlation between yields under stress and non-stress conditions are considered to be the best because they can separate genotypes with high yield in both conditions (Singh et al. 2015). In general, the MP, GMP, and DTI indices tended to classify the genotypes quite similarly once they are driven mainly by the yield/trait potential of the genotypes, and were appropriate to identify the cassava accessions with better agronomic attributes, regardless their drought tolerance. In contrast, DSI, SUS, and YSI are mainly based on smaller difference of the performance of the genotypes under irrigated and water-deficit conditions, and so were most 


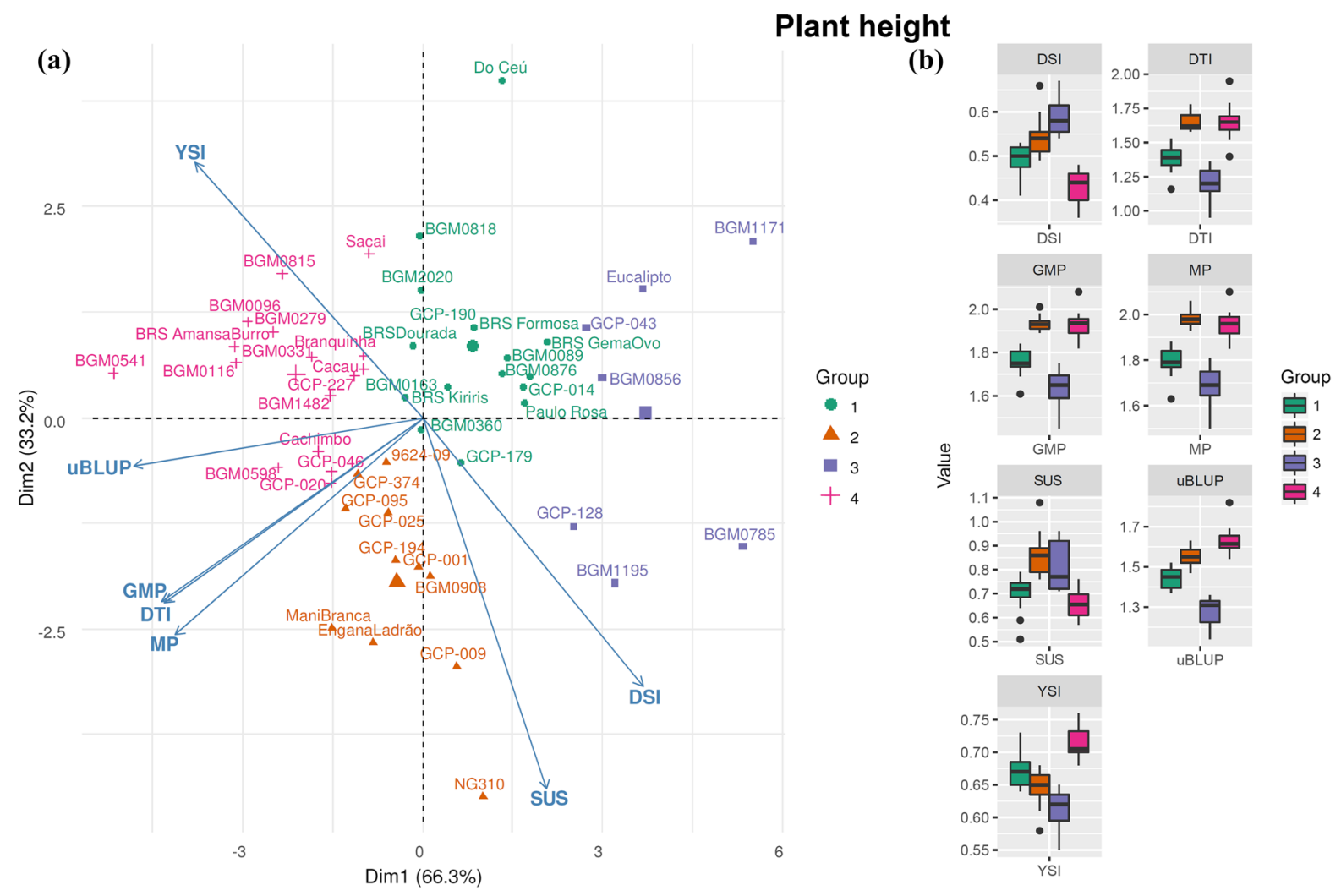

Fig. 5 a Principal component analysis of the 49 cassava accessions based on the best linear unbiased predictors plus the average of the experiments (uBLUP) for plant height and several drought tolerance indices. b Boxplot of plant height

suitable to identify the most tolerant accessions for all traits, although this tolerance was not associated with higher phenotypic mean of the selected genotypes, under water-deficit conditions. In other crops, such as wheat, significant correlations were also observed between grain yield and the MP, GMP, and DTI, indicating that these criteria discriminated droughttolerant genotypes with high grain yield in environments with and without water stress (El-Mohsen et al. 2015). However, the SUS presented a median and positive correlation only for productive traits (ShY and RoY) and a median and negative correlation for DMC, HI, and PH. Other authors have mentioned that taller cassava genotypes tend to show higher reductions when submitted to water stress (Bergantin et al. 2004; Chemonges et al. 2013).

The higher the SUS the greater the sensitivity to water stress; thus, low SUS values are more adequate in the selection process because they favor the
(uBLUP) and drought tolerance indices per group. MP mean productivity, GMP geometric mean productivity, SUS susceptibility, DTI drought tolerance index, DSI drought susceptibility index, and YSI yield stability index

selection of genotypes with high yield potential under stressed conditions. In other crops, such as sweet potato, the MP, GMP, and SUS also showed strong correlations between yields under water-stress conditions (Agili et al. 2012).

The DSI presented a low positive correlation for ShY and RoY and a high and negative correlation for DMC and PH, while the YSI presented contradictory results to the DSI, i.e., a low negative correlation for ShY and RoY and a high positive correlation for DMC and $\mathrm{PH}$. Therefore, in the present study with cassava, the SUS, DSI, and YSI indices were quite dependent on the trait under analysis. In other crops, such as wheat, no significant correlations were found between grain yields under water stress with the SUS, DSI, and YSI (ElMohsen et al. 2015), indicating that these indices may not be adequate for water stress analysis for several traits and different crops. 


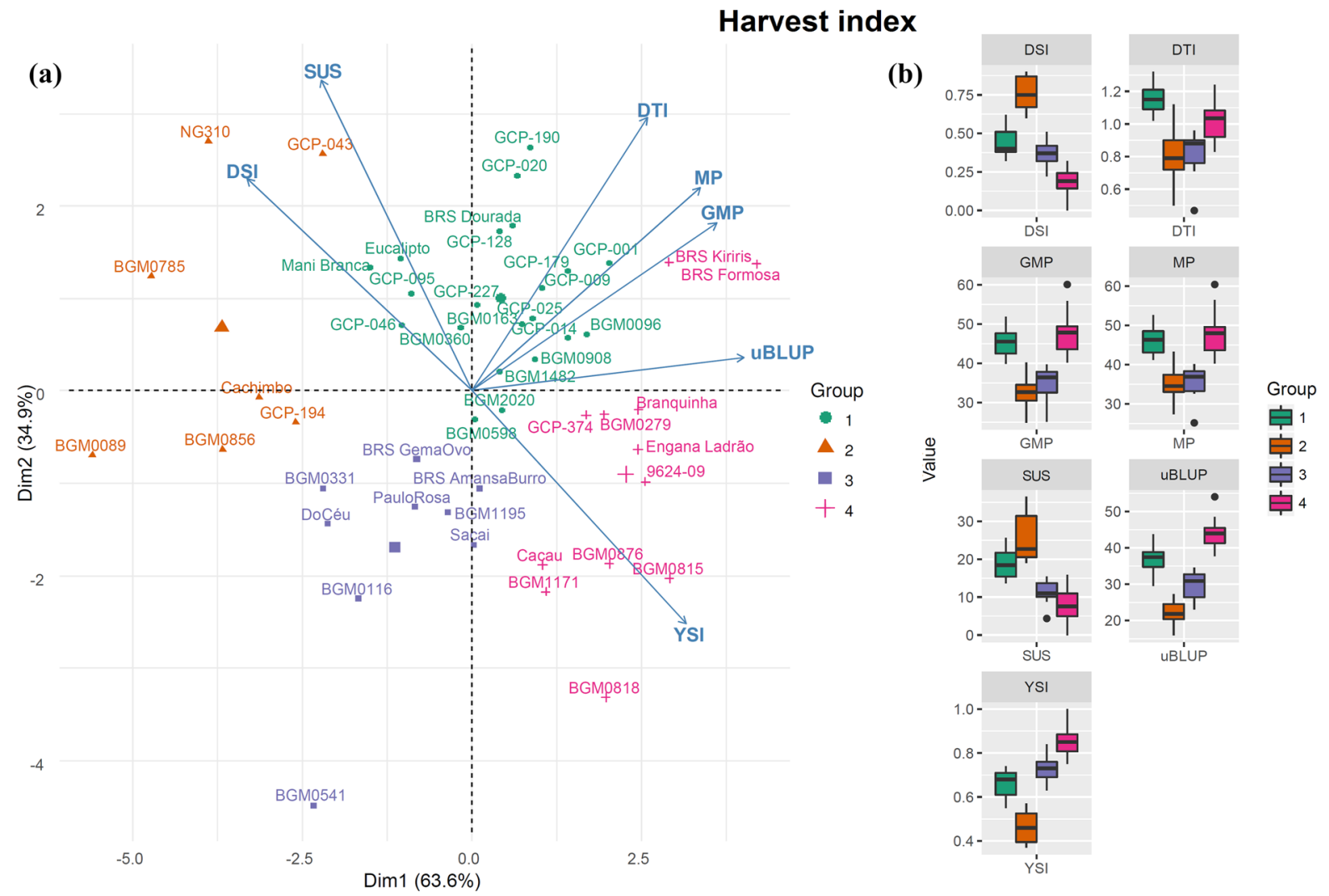

Fig. 6 a Principal component analysis of the 49 cassava accessions based on the best linear unbiased predictors plus the average of the experiments (uBLUP) for harvest index and several drought tolerance indices. b Boxplot of harvest index

Although some authors mention that the most adequate drought tolerance indices for genotype selection are those that show a high correlation with yield under both irrigation and stress conditions (Farshadfar et al. 2001), the difficulty and the cost of implementing field trials in both conditions makes selection under water stress preferable. Indeed, tolerance indices that rely on loss of yield under drought conditions compared to normal irrigation have been widely used in the selection of drought-tolerant genotypes (Agili et al. 2012). Recently, Lu et al. (2011) reported the development of multiple regression selection indices using drought-resistance criteria and yield components in maize. These authors reported that the models based on the droughttolerance criteria explained 38.6 and $42.0 \%$ of the variation for the grain yield in the FI and DS conditions, respectively, while the model based on yield components explained 96.5 and $95.3 \%$ of the
(uBLUP) and drought tolerance indices per group. $M P$ mean productivity, GMP geometric mean productivity, SUS susceptibility, DTI drought tolerance index, DSI drought susceptibility index, and YSI yield stability index

variation for grain yield under FI and DS conditions, respectively. Therefore, the results obtained based only on yield data under drought conditions were more useful to explain the phenotypic variation of the data under water stress.

\section{Clustering for drought tolerance}

The PCA results showed that the first two components explained more than $97 \%$ of the total variation for most of the traits evaluated and, therefore, show a good spatial representation of the drought tolerance indices and the behavior of the cassava accessions under these conditions. In cotton, Singh et al. (2015) also reported that the biplot analysis was able to explain more than $96 \%$ of the total variation of the yield data, and, therefore, it is a very useful tool to reduce the dimensionality and to facilitate the interpretation of the data. 
The clustering patterns for all traits evidenced the negative correlation between the DSI and YSI and the positive correlation between the DTI, GMP, MP, and uBLUP. Therefore, the use of PCA allowed the categorization of cassava accessions based on criteria of yield potential and susceptibility to drought stress. In general, accessions with a lower DSI and SUS and high YSI were classified as tolerant to water deficit, whereas accessions with a higher DTI, GMP, MP, and uBLUP were classified as having high agronomic performance. Thus, in all situations, it was possible to verify which accessions met one or another criterion, in order to facilitate the germplasm classification for drought tolerance. In wheat, selection based on the combination of tolerance indices also provided a more adequate criterion to select the most interesting accessions as well as to understand the degree of linear association between productive attributes and tolerance indices (Yasir et al. 2013).

The lack of an accession tolerant to water deficit for all five agronomic traits simultaneously is an inherent difficulty of the plant breeding. Accordingly, the cassava accessions were grouped based on criteria that involve greater tolerance to water stress in the aerial part and in the roots. In semiarid regions, greater aerial part production is a desirable feature because leaves and even stems are used in animal feed, especially during critical periods of drought. Consequently, accessions that produce abundant foliage are desirable as a food source under these conditions (Okogbenin et al. 2013). On the other hand, a more droughttolerant accession with the capacity to produce roots in these conditions has its importance as a cash crop for selling the roots in the market (in natura or processed as a product, such as flour or starch).

Perspectives for breeding cassava with better drought tolerance

The characterization of genetic diversity for drought tolerance and the identification of new germplasm is the first step toward the establishment of a conventional breeding program, genomic-assisted breeding, and functional analysis of genes involved in the various pathways associated with responses to water stress (Lu et al. 2011). Therefore, the success of hybridization in the breeding program of any species depends on the appropriate choice of germplasm to be used as a parent. Crossbreeding involving selected, contrasting, and high-performance parental germplasm for certain agronomic traits tends to result in maximum recombination and genetic variation in the derived progenies (Darkwa et al. 2016). In the present study, the most promising groups of cassava accessions to generate these segregated populations were those selected based on the major uBLUPs under water stress (BGM0815, BGM0598, 9624-09, BGM0818, and BRS Formosa) for RoY and ShY.

According to Okogbenin et al. (2013), cassava varieties with higher weight of the aerial part tend to present high RoY in water-deficit conditions. However, of the top ten accessions, only 40\% (BGM0818, BGM0598, BGM0815, and 9624-09) were ranked in the top ten for ShY and RoY simultaneously. Therefore, the most promising accessions based on drought tolerance indexes were also grouped based on the highest agronomic attributes related to shoot production (BGM0279, BGM0096, BRS Amansa Burro, Cachimbo, BGM0331, BGM0818, Do Ceú, and GCP190) and based on root production (BGM2020, BGM0876, BRS Gema de Ovo, Paulo Rosa, Cachimbo, BGM0116, BGM1171, GCP-128, and Eucalipto). For these reasons, this germplasm constitutes an excellent starting point for the generation of cassava varieties with high yield under water-stress conditions, and for several genomic studies to identify the genes evolved in drought tolerance.

Although cassava has been considered a crop with high drought tolerance, this statement is not valid for all $M$. esculenta germplasm since many genotypes have severe effects on plant phenology, phasic development, growth, assimilate partitioning, and plant reproduction processes (Aina et al. 2007). In recent years (2011-2016), the Northeast region of Brazil has been suffering from severe drought, and the susceptibility of most local varieties is seen as one of the major drawbacks for sustainable and durable production in such areas. Therefore, even in a limited set of accessions compared to the available cassava germplasm in Brazil, this work demonstrated the existence of enough genetic variability to develop in-depth studies on drought tolerance and to contribute to the reduction of food insecurity, particularly among the most vulnerable and poorest farmers living in semiarid regions. The development of new cassava varieties with better drought tolerance using this basic germplasm will increase crop yield, especially in regions where seasonal drought is a significant issue. Indeed, 
introduced germplasm from Latin America (especially from Northeast Brazil) has been providing a unique source of variability to further extend the genetic basis for drought tolerance, considering the expansion of cassava to nontraditional semiarid regions of subSaharan Africa (Aina et al. 2007).

It is assumed that traits that confer drought tolerance in cassava can be improved by breeding and selection, in order to develop varieties that will present high yield with a limited supply of soil moisture. Consequently, additional studies on the inheritance pattern of drought tolerance among different cassava genotypes will be necessary to establish the most adequate breeding methods to obtain maximum genetic gains in a short period of time. Although the understanding of the inheritance pattern of several relevant agronomic traits is a major challenge in cassava due to its heterozygous nature (Cach et al. 2006), the accumulation of genes for drought tolerance in improved material via recurrent selection constitutes a promising strategy for better adaptation of cassava germplasm to semiarid regions. In addition, other approaches involving the use of a genome-wide association study (GWAS) and genome selection (GS) currently in use in cassava (Oliveira et al. 2012; Azevedo et al. 2016; Wolfe et al. 2016) can elucidate the genetic control of drought tolerance, locate genes involved in drought tolerance, enable the selection of parents with high breeding value, and contribute to maximizing the productive potential in areas prone to drought.

\section{Conclusions}

Although cassava has been considered a crop with high tolerance to drought, the observations in our work indicate that there is great variability for this characteristic in M. esculenta, whereas production losses may reach up to 72.98 and $54.95 \%$ for root and shoot yield, respectively. In order to select cassava accessions with high drought tolerance, the phenotypic data regarding water deficit conditions, as well as several drought tolerance indexes, were analyzed. The clustering of accessions based on these data indicated that the MP, GMP and DTI indices were useful to identify the accessions with better agronomic performance, while DSI, SUS, and YSI were most appropriate to identify the most tolerant ones under water-deficit conditions. Therefore, in order to be considered drought tolerant, the cassava germplasm accessions need to survive throughout drought periods and also produce enough root and shoots. Thus, the genotypes were classified into accessions of high agronomic performance or with high drought tolerance for shoot and root economic attributes. The accessions selected in both groups have high value to guide breeding strategies to develop new cassava varieties. Moreover, these germplasm accessions can increase breeder's knowledge about the potential of yield increase under drought conditions and use this understanding in conventional or genomics studies for improving the genetic resolution and understanding of the biochemical pathways associated with this important abiotic stress.

Acknowledgements The authors thank the Fundação de Amparo à Pesquisa do Estado da Bahia (FAPESB), Coordenação de Aperfeiçoamento de Pessoal de Nível Superior (CAPES) and Conselho Nacional de Desenvolvimento Científico e Tecnológico (CNPq) for the financial assistance and scholarship support.

\section{References}

Adjebeng-Danquah J, Gracen VE, Offei SK, Asante IK, ManuAduening J (2016) Genetic variability in storage root bulking of cassava genotypes under irrigation and no irrigation. Agric Food Sec 5:9. doi:10.1186/s40066-0160055-7

Agili S, Nyende B, Ngamau K, Masinde P (2012) Selection, yield evaluation, drought tolerance indices of orange-flesh sweet potato (Ipomoea batatas Lam) hybrid clone. J Nutr Food Sci 2:138. doi:10.4172/2155-9600.1000138

Aina OO, Dixon AGO, Akinrinde EA (2007) Effect of soil moisture stress on growth and yield of cassava in Nigeria. Pak J Biol Sci 10:3085-3090

Alves AAC, Setter T (2004) Response of cassava leaf area expansion to water deficit: cell proliferation, cell expansion and delayed development. Ann Bot 94:605-613

Ambachew D, Mekbib F, Asfaw A, Beebe SE, Blair MW (2015) Trait associations in common bean genotypes grown under drought stress and field infestation by BSM bean fly. Crop J 3:305-316

Azevedo CF, Resende MDV, Silva FF, Viana JMS, Valente MSF, Resende MFR Jr, Oliveira EJ (2016) New accuracy estimators for genomic selection with application in a cassava (Manihot esculenta) breeding program. Genet Mol Res 15:4. doi:10.4238/gmr.15048838

Bates D, Maechler M, Bolker B, Walker S (2015) Fitting linear mixed-effects models using lme4. J Stat Softw 67:1-48

Bergantin VR, Yamauchi A, Pardales JR Jr, Bolatete DM Jr (2004) Screening cassava genotypes for resistance to water 
deficit during crop establishment. Philipp J Crop Sci 29:29-39

Bouslama M, Schapaugh WT (1984) Stress tolerance in soybean. Part 1: evaluation of three screening techniques for heat and drought tolerance. Crop Sci 24:933-937

Cabello R, Monneveux P, De Mendiburu F, Bonierbale M (2013) Comparison of yield based drought tolerance indices in improved varieties, genetic stocks and landraces of potato (Solanum tuberosum L.). Euphytica 193:147-156

Cach NT, Lenis JI, Perez JC, Morante N, Calle F, Ceballos H (2006) Inheritance of useful traits in cassava grow in subhumid conditions. Plant Breed 125:177-182

Cattivelli L, Rizza F, Badeck FW, Mazzucotelli E, Mastrangelo AM, Francia E, Marè C, Tondelli A, Stanca AM (2008) Drought tolerance improvement in crop plants: an integrated view from breeding to genomics. Field Crops Res 105:1-14

Chemonges M, Balyejusa EK, Bisikwa J, Osiru DSO (2013) Phenotypic and physiological traits associated with drought tolerant cassava cultivars in Uganda. Afr Crop Sci Conf Proceed 11:463-469

Darkwa K, Ambachew D, Mohammed H, Asfaw A, Blair MW (2016) Evaluation of common bean (Phaseolus vulgaris L.) genotypes for drought stress adaptation in Ethiopia. Crop J 4:367-376

Duque LO, Setter T (2013) Cassava response to water deficit in deep pots: root and shoot growth, ABA, and carbohydrate reserves in stems, leaves and storage roots. Trop Plant Biol 6:199-209

El-Mohsen AAA, El-Shafi MAA, Gheith EMS, Suleiman HS (2015) Using different statistical procedures for evaluating drought tolerance indices of bread wheat genotypes. Adv Agric Biol 4:19-30

El-Sharkawy MA (1993) Drought tolerant cassava for Africa, Asia and Latin America: breeding projects work to stabilize productivity without increasing pressures on limited natural resources. Bioscience 43:441-451

El-Sharkawy MA (2007) Physiological characteristics of cassava tolerance to prolonged drought in the tropics: implications for breeding cultivars adapted to seasonally dry and semiarid environments. Braz J Plant Physiol 19:257-286

El-Sharkawy MA (2012) Stress-tolerant cassava: the role of integrative ecophysiology-breeding research in crop improvement. Open J Soil Sci 2:162-186

Farshadfar E, Ghannadha M, Zahravi M, Sutka J (2001) Genetic analysis of drought tolerance in wheat. Plant Breed 114:542-544

Fernandez GCJ (1992) Effective selection criteria for assessing plant stress tolerance. In: Kuo CG (ed) Adaptation of food crops to temperature and water stress. Asian Vegetable Research and Development Center, Shanhua, pp 257-270

Fischer RA, Maurer R (1978) Drought resistance in spring wheat cultivars. I. Grain yield responses. Aust J Agric Res 29:897-912

Friendly M (2002) Corrgrams: exploratory displays for correlation matrices. Am Stat 56:316-324

Fu L, Ding Z, Han B, Hu W, Li Y, Zhang J (2016) Physiological investigation and transcriptome analysis of polyethylene glycol (PEG)-induced dehydration stress in cassava. Int $\mathbf{J}$ Mol Sci 17:3. doi:10.3390/ijms17030283
Hossain ABS, Sears AG, Cox TS, Paulsen GM (1990) Desiccation tolerance and its relationship to assimilate partitioning in winter wheat. Crop Sci 30:622-627

IBGE (Instituto Brasileiro de Geografia e Estatística) (2016) Censo Agropecuário. https://sidra.ibge.gov.br/pesquisa/ pam/tabelas. Accessed 5 Jan 2017

Kassambara A, Mundt F (2016) Factoextra: extract and visualize the results of multi-variate data analyses. $\mathrm{R}$ package version 1.0.3. www.sthda.com/english/rpkgs/factoextra/. Accessed 16 Oct 2016

Kawano K, Fukuda WMG, Cenpukdec U (1987) Genetic and environmental effects on dry matter content of cassava root. Crop Sci 27:69-74

Lu Y, Hao Z, Xie C, Crossa J, Araus JL, Gao S, Vivek BS, Magorokosho C, Mugo S, Makumbi D, Taba S, Pan G, Li X, Rong T, Zhang S, Xu Y (2011) Large-scale screening for maize drought resistance using multiple selection criteria evaluated under water-stressed and well-watered environments. Field Crop Res 124:37-45

Okogbenin E, Ekanayake IJ, Porto MCM (2003) Genotypic variability in adaptation responses of selected cassava clones to drought stress in the Sudan Savannah Zone of Nigeria. J Agron Crop Sci 189:376-389

Okogbenin E, Setter TL, Ferguson ME, Mutegi R, Ceballos H, Olasanmi B, Fregene M (2013) Phenotypic approaches to drought in cassava: review. Front Physiol 4:1-15

Oliveira EJ, Rezende MDV, Santos VS, Ferreira CF, Oliveira GAF, Silva MS, Oliveira LA, Aguilar-Vildoso CI (2012) Genome-wide selection in cassava. Euphytica 187:263-276

Oliveira EJ, Aidar ST, Morgante CV, Chaves ARM, Cruz JL, Coelho Filho MA (2015) Genetic parameters for droughttolerance in cassava. Pesqui Agropecu Bras 50:233-241

Oliveira EJ, Santos PEF, Pires AJV, Tolentino DC, Santos VS (2016) Selection of cassava varieties for biomass and protein production in semiarid areas from Bahia. Biosci $\mathrm{J}$ 32:661-669

Rizza F, Badeck FW, Cattivelli L, Destri L, Di Fonzo O, Stanca N (2004) Use of a water stress index to identify barley genotypes adapted to rainfed and irrigated conditions. Crop Sci 44:2127-2137

Rosielle AA, Hamblin J (1981) Theoretical aspects of selection for yield in stress and non-stress environments. Crop Sci 21:943-946

Shirani Rad AH, Abbasian A (2011) Evaluation of drought tolerance in rapeseed genotypes under non stress and drought stress conditions. Not Bot Horti Agrobot Cluj Napoca 39:164-171

Singh C, Kumar V, Prasad I, Patil VR, Rajkumar BK (2015) Response of upland cotton (G. hirsutum L.) genotypes to drought stress using drought tolerance indices. J Crop Sci Biotech 19:53-59

Tonukari NJ (2004) Cassava and the future of starch. Electron J Biotechnol 7:1-4

Voltas J, Lopez-Corcoles H, Borras G (2005) Use of biplot analysis and factorial regression for the investigation of superior genotypes in multi environment trials. Eur J Agro 22:309-324

Wolfe MD, Rabbi IY, Egesi C, Hamblin M, Kawuki R, Kulakow P, Lozano R, Del Carpio DP, Ramu R, Jannink J-L (2016) Genome-wide association and prediction reveals genetic 
architecture of cassava mosaic disease resistance and prospects for rapid genetic improvement. Plant Genome 9:1-13

Yasir TA, Chen X, Tian L, Condon AG, Hu Y-G (2013) Screening of Chinese bread wheat genotypes under two water regimes by various drought tolerance indices. Aust J Crop Sci 7:2005-2013
Zhao P, Liu P, Shao J, Li C, Wang B, Guo X, Yan B, Xia Y, Peng M (2015) Analysis of different strategies adapted by two cassava cultivars in response to drought stress: ensuring survival or continuing growth. J Exp Bot 66:1477-1488 